\title{
Nietzsche y los filósofos de la diferencia*
}

\author{
Diana M. Muñoz González** \\ Le moment est désormais venu pour moi, \\ de revenir au monde comme Français ${ }^{1}$. \\ Nietzsche, 1888
}

\section{Resumen}

La gran influencia de Nietzsche en la filosofía francesa de las últimas décadas del siglo veinte puede ser vista como la inspiración principal para el surgimiento de la llamada «Filosofía de la diferencia». Este artículo retraza los momentos clave de esta influencia, ligando particularmente el resurgimiento de Nietzsche a finales de los años sesenta con la reacción provocada por la poderosa lectura de Heidegger, cuya búsqueda hermenéutica del fundamento y unidad últimas de la filosofía nietzscheana pareció ignorar, según la joven generación de filósofos franceses, la indomable pluralidad de sentidos al interior de los textos del autor del Zaratustra, así como los alcances que su pensamiento radical tendría en la creación de nuevas maneras de filosofar.

\footnotetext{
* $\quad$ Este artículo es resultado del Proyecto de Investigación «Nietzsche en la filosofía francesa contemporánea» desarrollado en la Facultad de Filosofía con el auspicio de la Dirección de Investigaciones de la Universidad de San Buenaventura, Bogotá. Investigadora principal: Diana Muñoz G., Ph. D., Profesora Asociada.

** Pregrado en Filosofía de la Universidad Nacional de Colombia, Magíster en Filosofía de la misma Universidad y Doctorado en Filosofía de la Universidad Paris 8. Miembro de «Devenir», Grupo de Investigación en Filosofía Contemporánea. Actualmente se desempeña como profesora de tiempo completo en la Facultad de Filosofía de la Universidad de San Buenaventura, teniendo a su cargo, entre otros, el módulo de Maestría en «Filosofía de la Diferencia». Contacto: dmunoz@usbbog.edu.co

1 «El momento ha llegado para mí de volver al mundo como un francés». La traducción de esta cita, así como la de todas las que en adelante aparecen en el artículo, es mía.
} 


\section{Palabras clave}

Nietzsche, Heidegger, filosofía francesa, postestructuralismo, diferencia.

\section{Nietzsche and the Philosophers of Difference}

\section{Abstract}

Nietzsche's great influence on contemporary French philosophy, especially during the last decades of the twentieth century, might be considered as the main inspiration for the emergence of the so-called «philosophy of difference». This paper retraces the key moments of that influential presence, relating the event of Nietzsche's revival in the late sixties with the effect generated in France by the powerful interpretation offered by Heidegger. An interpretation, whose hermeneutical research for the foundation and definite unity of the nietzschean thought, seemed to overlook, according to the young generation of French philosophers, the untamable plurality of meanings within Nietzsche's texts, as well as the potentiality that his radical thinking entailed in creating new ways of philosophizing.

\section{Keywords}

Nietzsche, Heidegger, French philosophy, post-structuralism, difference.

En virtud de la indiscutible presencia de Nietzsche en la filosofía francesa contemporánea, no carece de interés preguntar si su pensamiento constituyó el impulso principal de la denominada «Filosofía de la diferencia» desarrollada desde finales de los años sesenta en Francia. En otras palabras, si acaso es acertado decir que sin el redescubrimiento de Nietzsche por parte de la nueva generación de filósofos de ese país, la intelligentsia del momento no habría encontrado 
ni liberado el cauce intelectual necesario para forjar esos nuevos y audaces caminos de pensamiento que condujeron a la diferencia como problema filosófico preeminente. Esta afirmación, que a primera vista parece sobreestimar el papel del filósofo alemán al atribuirle una influencia tan decisiva, no es sin embargo ajena a la opinión de varios comentaristas para quienes Nietzsche brindó, en efecto, la fuerza que esa nueva generación necesitaba para canalizar su aspiración de revuelta en contra de la filosofía tradicional y, sobre todo, en contra de las, a sus ojos, anquilosadas instituciones académicas. El recurso a Nietzsche les habría permitido oxigenar el aire ya mustio que para ellos exhalaba la filosofía practicada hasta entonces, al tiempo que les daba eficaces medios conceptuales para salir al paso a los excesos que a su juicio cometían las ciencias humanas, crecidas entonces por la imparable ola estructuralista, cuyo auge amenazaba con arrinconar definitivamente a la filosofía. Al respecto, Alan D. Schrift escribe:

El "nietzscheanismo francés" caracteriza a la filosofía post-estructuralista porque, en un buen número de sentidos, es por la apropiación de los temas nietzscheanos que los filósofos post-estructuralistas se distinguieron a la vez de los estructuralistas y del establishment filosófico que buscaban desafiar. (...) Nietzsche aparecía a sus lectores como un autor a la vez filosóficamente inspirado y filosóficamente inspirador ${ }^{2}$.

En efecto, aunque no resulta correcto afirmar que la expresión «filosofía de la diferencia» reúne bajo una consigna o doctrina común al grupo de filósofos franceses asociados con ella (Derrida, Deleuze, Lyotard y Foucault), se habla con frecuencia de un cierto aire de familia que los acerca. Tal atmósfera común, o eso que Vincent Descombes llama de forma algo difusa air du temps o el aire de la época que 
respiran los trabajos de aquel momento ${ }^{3}$, estaría, pues, constituido en buena medida por el aliento de Nietzsche; un hálito contagioso que con inusitada fuerza insufló vida a los respectivos proyectos filosóficos de estos pensadores, si bien conduciéndolos por caminos separados ${ }^{4}$. Ciertamente, la familiaridad que los vincula, no obstante el carácter profundamente independiente y la poca influencia directa que el trabajo de los unos parece haber tenido sobre el de los otros ${ }^{5}$, obedecería en último término a su estrecho parentesco con Nietzsche: en cierto modo, son todos «hijos» suyos. De hecho, se ha vuelto usual que respecto a estos cuatro autores, y al periodo de su mayor producción, se hable ya con cierta naturalidad de «nietzscheanismo francés». Del filósofo alemán habrían heredado, para comenzar, el talante rebelde de un modo de pensamiento original que difícilmente se deja clasificar sin incurrir con ello en una simplificación estéril ${ }^{6}$.

Vincent Descombes, Lo mismo y lo otro. Cuarenta y cinco años de filosofía francesa (Madrid: Cátedra, 1998), 13.

Criticando la tendencia que existe, especialmente en Estados Unidos, a imponer una etiqueta que dé cuenta del rasgo esencial compartido por distintos autores franceses, pasando así por alto las diferencias profundas que existen entre ellos, Schrift comenta lo siguiente: "[En Francia], en cambio, cada uno de estos pensadores es considerado como teniendo un proyecto distinto, de modo que solo raramente se estudian sus trabajos conjuntamente, y esto solo por quienes simpatizan con ellos. En realidad, solo de cuando en cuando se puede encontrar a alguien que se ocupa de Deleuze y de Foucault al tiempo, o que discute Derrida y Lyotard simultáneamente, pero casi nunca se encuentran en el medio académico francés trabajos que pongan en discusión a Derrida o Deleuze, o a Foucault y a Derrida». Sin duda, esta ausencia de trabajos especializados que busquen poner en relación directa a unos con otros puede ser tomada como un indicador bastante elocuente del hecho de que se trata efectivamente de empresas filosóficas muy independientes entre sí, sin puntos de contacto evidentes que permitieran hablar de una «filosofía común». Lo de la «French Theory» de la que tanto se habla al otro lado del Atlántico tiene, pues, más de un label publicitario que dé verdadera descripción de un proyecto filosófico con rasgos más o menos homogéneos. En Alan Schrift, Twentieth-Century French Philosophy. Key Themes and Thinkers (Great Britain: Blackwell Publishing, 2006), 54.

5 Como advierte Cristian Ruby: «Las filosofías de la diferencia es un término empleado por comodidad en la medida en que estas filosofías no constituyen ni un cuerpo unificado, ni un campo de referencia único». Christian Ruby, Les Archipels de la Différence. Foucault-Derrida-Deleuze-Lyotard (Paris: Éditions du Félin, 1989), 14. Llamemos la atención sobre el plural empleado aquí por Ruby, el cual refuerza la idea de que, aun si la diferencia parece ser un problema «común» para estos pensadores incluso no puede hacerse de este el punto de intersección que los haga converger con total claridad, primando en realidad una pluralidad irreductible de puntos de vista. Esta pluralidad es lo que el autor recoge con su ilustrativa imagen del «archipiélago» en el que cada uno de los autores constituye una isla junto a otras.

6 El calificativo de «rebeldes» es empleado con relativa frecuencia para referirse al talante profundamente innovador e iconoclasta de los trabajos realizados por estos filósofos que «sin cesar ponen en cuestión el poder, la institución y la manera misma de pensar y de filosofar». Catherine Halpern, «Éditorial», Magazine Sciences Humaines. Numéro Spécial Hors-Serie N. ${ }^{\circ}$ 3. Foucault-DerridaDeleuze: Pensées rebelles (2005). 
Nuestro propósito en lo que sigue es llegar a situar, si bien solo de forma preliminar, el impacto que Nietzsche tuvo en esa generación de franceses denominados con el apelativo que, insistamos, no conviene tomar sino de modo indicativo, de «filósofos de la diferencia». Ciertamente, interesa poner a prueba la idea según la cual fue la obra de aquel-ío quizás su ejemplo?- lo que constituyó la inspiración decisiva para las empresas filosóficas de estos, al punto que sería posible decir que sin su tutela no habrían encontrado los medios expresivos que sus novedosas estrategias de pensamiento requerían, y que caracterizan ese momento tan singular de la filosofía que se dio en Francia en las últimas décadas del siglo pasado.

Ahora bien, parece necesario preguntarse si no incurre en un énfasis injustificado la afirmación que hace descansar en el influjo de Nietzsche, más que en el de ningún otro autor, corriente, obra o acontecimiento, la emergencia y desarrollo de estos proyectos algo inéditos. ¿̇No hubo tal vez otros factores, tanto o más determinantes, que con su energía perturbadora los pusieron en movimiento? Baste pensar en el auge desmedido del estructuralismo -movimiento que dominaba por aquel entonces la escena intelectual y académica francesa- y en el declive concomitante de la filosofía en boga, en particular del existencialismo y la fenomenología, como factores que seguramente obligaban a buscar otros puntos de referencia desde los cuales dar cuenta de la crisis de la filosofía. En efecto, el hecho de que antes de imponerse el apelativo de «filosofía de la diferencia» fuera más habitual referirse a este grupo de autores como «postestructuralistas», deja ver en qué medida el estructuralismo constituía el telón de fondo en prolongación y en reacción al cual se levantaron estos nuevos proyectos filosóficos, dando esto razones para concluir que es más bien al hilo de su relación con el movimiento estructuralista, más que de su relación con Nietzsche, que habría de explicarse el surgimiento de estas empresas filosóficas «en torno a» la diferencia.

De otro lado, ¿̇por qué no pensar que quizás merecería igual, o hasta mayor atención, la influencia ejercida por el psicoanálisis 
y/o el marxismo, ya que junto a Nietzsche, Freud y Marx son los otros dos autores que conforman ese célebre trío denominado por Ricoeur «los maestros de la sospecha», y cuyo efecto sobre la nueva generación terminó por eclipsar el papel que hasta entonces ejercían las canónicas tres Hs (Hegel, Husserl y Heidegger), esa otra constelación de pensadores alemanes que dominó el universo de la generación precedente de filósofos franceses (Hyppolite, Sartre, Merleau-Ponty, etc.)? Efectivamente, uno de los acontecimientos que con frecuencia se señala como síntoma del quiebre profundo que separó a la nueva generación de sus antecesores es el relevo que sufrieron las figuras tutelares bajo cuyo auspicio se situaban unos y otros ${ }^{7}$. ¿No habría entonces que leer las filosofías de la diferencia a contraluz del marxismo y/o el psicoanálisis también dominantes, y no solo ni principalmente del nietzcheanismo? Muy seguramente, como reconoce Alan Schrift, el postestructuralismo admite otras genealogías distintas a la que se centra específicamente en la relación con Nietzsche ${ }^{8}$. También queda por ver si en realidad puede afirmarse un total desplazamiento de las hasta entonces figuras tutelares, pues como lo plantea Dominique Janicaud en su voluminosa y detallada obra sobre la recepción de Heidegger en Francia $^{9}$, mucho de lo ocurrido en la filosofía francesa de la posguerra puede explicarse por la inusual y creativa recepción que se hiciera de Heidegger, en la medida en que su filosofía parecía ofrecer los recursos teóricos necesarios para escapar del tan arraigado cartesianismo.

¿Por qué no, finalmente, subrayar con igual fuerza fenómenos como la pérdida de valor del ideal de progreso, unida a la herida todavía dolorosa de la Segunda Guerra, así como el malestar generado por las tensiones constantes de la Guerra Fría y el descrédito creciente de las ideologías políticas de izquierda, sin mencionar los profundos cambios económicos, políticos y sociales que, en cierto modo, tuvieron

7 Cf. Frédéric Worms, «Structure et différence: Le moment philosophique des années soixante en France» en Moments. La philosophie en France au xxème siècle (Paris: Gallimard, 2009), 467-490.

8 Cf. Alan D. Schrift, Nietzsche's French Legacy. A Genealogy of Poststructuralism (New York/London: Routledge, 1995), Preface.

9 Cf. Dominique Janicaud, Heidegger en France, 2 Vols. (Paris: Albin Michel, 2001). 
su clímax en el célebre Mayo del 68, como detonantes igualmente poderosos de nuevas búsquedas de sentido al margen de la tradición filosófica? No hay duda de que estos y otros acontecimientos críticos dibujaron el escenario en el que tuvo lugar el surgimiento de los discursos de esta nueva generación de filósofos. Acontecimientos tan significativos que merecerían un lugar central como factores que, junto con el influjo de Nietzsche, explicarían el surgimiento de estos nuevos modos de pensamiento forjados en torno al problema de la diferencia. Ciertamente, fenómenos que ponían de presente la urgencia de llevar a cabo una profunda autocrítica por parte de Occidente, en la medida en que desbordaban y ponían en jaque los medios de comprensión ofrecidos por la tradición filosófica, en particular, el recurso a las categorías de universalidad, identidad, totalidad, autoridad, etc., categorías que comenzaron a ser vistas, precisamente, como estando a la raíz de tantas violencias y desmanes ocurridos en la historia occidental. Vistas así las cosas, probablemente Nietzsche no deba ser tratado como el cauce central, sino más bien como una más de las vertientes a través de las cuales debía fluir ese irreprimible deseo de ruptura y de renovación que caracterizó a esa joven generación de filósofos, sensibles a los apremiantes reclamos de esta época inédita.

Con todo, aun si parece algo unilateral pensar la figura de Nietzsche como la que, más que ninguna otra, promovió con su influjo el surgimiento de la «filosofía de la diferencia» en Francia, y pese a que un examen más cuidadoso de la cuestión obligue seguramente a morigerarnos y a corregir el exceso de esta apreciación inicial, mantengamos de momento esta hipótesis con el ánimo de facilitar, desde un punto de vista metodológico, la comprensión de este momento singular en el pensamiento filosófico contemporáneo. En efecto, parece posible que al servirnos de Nietzsche como del autor en diálogo con el cual estos autores habrían labrado su propia ruta de pensamiento, se encuentre una privilegiada vía de acceso hacia el encuentro con cada uno de ellos, y se asegure una mejor comprensión de los motivos y los alcances de las llamadas «filosofías de la diferencia». 


\section{El redescubrimiento de Nietzsche}

Durante la década de los sesenta el redescubrimiento de Nietzsche se puede ver como el hecho que permitió a la nueva generación de pensadores franceses encontrar su propia voz y, mejor aún, el que les dio el impulso necesario para desarrollar un pensamiento que, a contrapelo de buena parte de la tradición filosófica, hizo de la diferencia y no de la identidad su leitmotiv conceptual. Sin embargo, lo cierto es que no resulta del todo claro que pueda hablarse precisamente de «redescubrimiento». Basta lanzar una mirada rápida a la historia de la recepción de Nietzsche en Francia para darse cuenta de que, en estricto sentido, Nietzsche nunca ha dejado de estar presente en el ámbito intelectual en ese país, y que su influencia allí se ha hecho sentir con fuerza casi ininterrumpida a lo largo de los más de cien años que ya cuenta esta historia. De hecho, puede decirse que desde que Nietzsche cautivó a los franceses, lo que ocurrió por cierto muy temprano, la fascinación por él nunca ha cesado, volviendo así difícil hablar de un redescubrimiento, como si en algún momento de esta historia efectual hubiera prevalecido el olvido o la indiferencia hacia su obra. Entonces, ¿̇por qué hablar en estos términos? ¿ Dónde se sitúa y en qué consiste ese punto de inflexión decisivo que, por así decir, revitalizó a Nietzsche en Francia al punto de sugerir que se trató de un nuevo descubrimiento de su pensamiento? ${ }^{10}$. Para responder a esto conviene repasar algunos de los momentos más importantes en esa recepción.

En un breve artículo que lleva el elocuente título «Nietzsche, una pasión francesa. Cien años de recepción de Nietzsche en Francia» ${ }^{11}$, Jacques Le Rider sintetiza las etapas más importantes del siglo de

10 «Nietzsche tuvo una importante influencia en todos estos pensadores, muchos de los cuales contribuyeron a lo que se ha dado a conocer como la "resurrección de Nietzsche" en Francia en las décadas de los 60 y 70». Ashley Woodward, Understanding Nietzscheanism (Durham: Acumen, 2011), 67.

11 Jacques Le Rider, «Nietzsche, una pasión francesa. Cien años de recepción de Nietzsche en Francia», Revista Enrahonar. Quaderns de Filosofia 35 (2002): 89-100. Traducción de Gerard Vilar. Un estudio mucho más detallado y profundo de este tema se encuentra en Jacques Le Rider, Nietzsche en France, de la fin du XIX siècle au temps présent (Paris: PUF, 1999). 
recepción de Nietzsche en el país galo. Un aspecto interesante del recorrido que allí se traza es la constatación de que la recepción del filósofo en la esfera intelectual y cultural francesa no fue de carácter póstumo, puesto que se remonta a finales del siglo XIX, en vida misma de Nietzsche, y, además, que pese a ciertos altibajos su influencia al otro lado del Rin no ha desaparecido nunca en todo ese lapso de tiempo. Hay que subrayar que esta relación estrecha de Francia con Nietzsche estuvo auspiciada por el mismo filósofo alemán, quien desprovisto de todo patriotismo vano declaró en varias ocasiones su profunda afinidad con el espíritu francés, al que decía preferir en lugar del «pesado»y «serio» espíritu germano del cual renegaba sin empacho ${ }^{12}$. Esto hace hablar a Le Rider del «afrancesamiento» de Nietzsche como un factor que seguramente favoreció esa inusitada acogida de Nietzsche, rápidamente considerado «un francés entre franceses ${ }^{13}$. Ciertamente, Nietzsche dejó saber en varias oportunidades que confiaba en que probablemente serían oídos franceses, según él los más finos y sutiles, los que un día por venir, estarían mejor capacitados para escuchar lo que entonces él anunciaba de un modo que, entre los suyos, no podía sino resultar intempestivo y disonante, y para lo cual solo algunos pocos, si acaso algunos, estaban listos.

De esta prolongada historia que Le Rider, al igual que otros comentaristas, divide en varias etapas ${ }^{14}$, conviene destacar el hecho de que la

12 «También ahora continúa siendo Francia la sede de la cultura más espiritual y refinada de Europa». Friedrich Nietzsche, Más allá del bien y del mal. § 254 (Madrid: Alianza Editorial, 1990), 210. A este respecto vale mencionar el libro de G. Campioni acerca de las lecturas francesas de Nietzsche, en el que el autor italiano ofrece un análisis muy detallado de la influencia que sobre el filósofo alemán ejercieron varios autores franceses de la época, rastreando de qué modo algunas ideas provenientes de Francia inspiraron o dieron impulso a sus propias reflexiones filosóficas. Giuliano Campioni, Lectures françaises de Nietzsche (Paris: PUF, 2001).

13 Este es precisamente el título que lleva una reciente compilación organizada por la especialista en Nietzsche, Scarlett Marton, en la que se reúnen ensayos escritos por varios filósofos franceses contemporáneos sobre la influencia de Nietzsche sobre distintas generaciones de filósofos en Francia. Scarlett Marton, Nietzsche: Um «frânces» entre franceses (São Paulo: Barcarolla, Discurso Editorial, 2009).

14 1. El nietzscheanismo francés de finales del s. XIX hasta 1914; 2. El período de entreguerras (19141918) y el Tercer Reich, 3. Los «locos por Nietzsche», 4. El período anterior a los años sesenta y, finalmente, 5. del Coloquio de Royaumont (1964) hasta hoy día. Para un muy completo estudio de la recepción francesa de Nietzsche, en el que se persiguen las múltiples transformaciones que sufrió «su» filosofía según los intereses interpretativos de cada momento, ver también: Louis Pinto, Les neveux de Nietzsche. La réception de Nietzsche en France (Paris: Seuil, 1995). 
recepción que desde el comienzo se hizo de Nietzsche en Francia fue muy favorable. Estando él aún con vida se hace la traducción al francés de algunos de sus últimos libros, publicados antes de sobrevenirle la noche de la locura ${ }^{15}$. Puede decirse que Francia sirvió muy pronto como caja de resonancia para la obra nietzscheana, al punto que, como lo afirma Gide en un irónico comentario del año 1898, aún antes de que la obra llegara a Francia, sus efectos la habían ya precedido con tanta fuerza, que fueron estos los que allanaron el camino a la obra misma. La acogida entre los franceses fue, pues, desde el principio, muy entusiasta $^{16}$. Desde entonces, Nietzsche ya era percibido como una figura mayor de la cultura europea, «faro de la modernidad», escritor visionario que había sabido capturar el espíritu de los tiempos, e incluso se le concedió el estatuto de «profeta». Gide, Proust y otros escritores franceses no dudaron en situarlo a la par de grandes figuras de la historia del pensamiento occidental, y a pesar de las distancias y tensiones entre los dos países, se veía en él un lazo de unión franco-alemán.

No obstante, esta recepción positiva se vio perturbada tiempo después por la imagen que la hermana de Nietzsche quiso imponer de la filosofía de este, vinculándola de forma grosera e infundada con el antisemitismo y el pangermanismo. Nietzsche fue efectivamente objeto de una abusiva apropiación por parte del Movimiento Nacional Socialista que hizo de él su filósofo de cabecera. Este vínculo, ahora plenamente desvirtuado, oscureció, sin embargo, su recepción en lo político donde, según muestra Le Rider, Nietzsche dio para alimentar

Ernst Behler recuerda de forma anecdótica el enorme orgullo que parecía sentir Nietzsche al saber que su obra encontraba en varias partes del mundo una recepción destacada, siendo desde entonces, según se complacía el filósofo alemán, objeto de estudio de los espíritus más sobresalientes y geniales de su tiempo. París era, por supuesto, uno de tales lugares donde, como Nietzsche consignara complacido en el Ecce Homo, la gente se mostraba muy receptiva a «toutes mes audaces et finesses». Cf. Ernst Behler, «Nietzsche in the twentieth century» en Cambridge Companion to Nietzsche (Cambridge: Cambridge University Press, 1996), 281-322.

16 Cf. Werner Hamacher (Hrsg), Nietzsche aus Frankreich. Essays von Maurice Blanchot, Jacques Derrida, Pierre Klossowski, Philippe Lacoue-Labarthe, Jean-Luc Nancy und Bernard Pautrat (Frankfurt/M; Berlin: Ullstein, 1986), 5-14. Hamacher se sirve de este comentario de Gide para afirmar, en una clave muy hermenéutica, que no hay obra sin efectos o, mejor aún, que la identidad de una obra es, en realidad, el producto de sus efectos y no algo que los anteceda y determine, idea que, sin duda, dice Hamacher, complacería mucho al mismo Nietzsche quien insistió sobre el carácter ficticio y secundario del autor entendido como sujeto soberano de su obra. 
lecturas de derecha como también, paradójicamente, de izquierda. Un nombre en particular merece especial atención en esta historia de la fascinación francesa por Nietzsche: el de Georges Bataille, quien en un tono exaltado declararía que Nietzsche era su única compañía en este mundo. Bataille se propuso, entre otras, la tarea de depurar la obra de Nietzsche de cualquier nexo ideológico con el Nazismo, y encontró en él, así como ocurrió con otros escritores de vanguardia (Valéry, p. ej.), un inspirador mayor de sus propias ideas, y, sobre todo, un aliado en su crítica a Hegel.

Podría llamar la atención el que haya sido entre literatos y artistas antes que en el círculo de los filósofos, entre quienes Nietzsche alcanzó mayor reconocimiento en un primer momento. Sin embargo, hay que decir que este no es un fenómeno exclusivo de la recepción francesa, pues también en Alemania fueron sobre todo escritores como Hermann Hesse, Rainer Maria Rilke, Thomas Mann, y músicos como Johann Strauss y Arnold Schönberg los que, antes que los filósofos, se sintieron atraídos por Nietzsche y su filosofía ${ }^{17}$. Y es que durante mucho tiempo prevaleció cierto prejuicio según el cual, por su forma de expresión hiperbólica y estilísticamente inusual, Nietzsche era tenido más por un poeta o por un artista que por filósofo en sentido estricto, lo cual retardó bastante la tarea de pensar «la» filosofía de Nietzsche -quizás hasta las lecturas de Jaspers y Heidegger en Alemania ${ }^{18}$-. Tampoco contribuyó a este propósito la

«Desde comienzos de la última década del siglo diecinueve, la presencia de Nietzsche dominó ampliamente la escena literaria de Alemania, y podría decirse sin lugar a dudas que difícilmente había algún autor que en uno u otro momento de su carrera no hubiera experimentado su paso por Nietzsche». Ernst Behler, «Nietzsche in the twentieth century» en Cambridge Companion to Nietzsche, ed. Bernd Magnus and Kathleen Higgins (Cambridge: Cambridge University Press, 1996), 298.

18 Cf. Hans Sluga, «Heidegger's Nietzsche» en A Companion to Heidegger. Edited by Hubert Dreyfus and Mark Wrathall (London: Blackwell, 2006), 102-120. Según este comentarista, Heidegger prolonga, aunque de un modo más radical, el gesto previo de las lecturas realizadas por estos dos autores, quienes, a contracorriente de la interpretación usual, insistieron en ver a Nietzsche como un pensador metafísico. Un mérito semejante tiene la lectura de Walter Kaufmann quien con su «Nietzsche» de 1950 logró pintar para los lectores norteamericanos un retrato de Nietzsche como «filósofo con un lugar en la gran tradición del pensamiento occidental, a la par de Sócrates y Platón, Lutero y Rousseau, Kant y Hegel y no solamente, como se ha dicho usualmente, un discípulo díscolo de Schopenhauer o un epígono solitario de los presocráticos». En Walter Kaufmann, Nietzsche. Philosopher, Psychologist, Antichrist (Princeton: Princeton Univesity Press, 1974) Cuarta edición. Prefacio. 
curiosidad enorme que despertaba la exuberante personalidad del autor y que muy a menudo llegó a eclipsar el interés por su obra. En Francia este prejuicio pareció perdurar durante un largo rato, si atendemos a la particular anécdota que recuerda Le Rider acerca de una conferencia dictada por Sartre hacia 1937, de la que al parecer no queda copia alguna, y cuyo título resulta bastante diciente: «i̇s Nietzsche un filósofo?». La presentación sartreana respondía a esta pregunta de manera negativa, sin que esta conclusión hubiera suscitado el desacuerdo del auditorio que la seguía en la ENS ${ }^{19}$.

Ahora bien, es difícil precisar el momento particular en que el interés por Nietzsche se desplaza de la escena artística francesa a los círculos académicos, y en particular, al ámbito filosófico. En este cambio destaca el papel jugado por Pierre Klossowski, quien, además de los juiciosos escritos que dedicó a la filosofía de Nietzsche, especialmente su «Nietzsche y el círculo vicioso», tradujo al francés el Nietzsche de Heidegger. Ciertamente, podría decirse que el cambio mencionado tuvo sobre todo que ver con el impacto que en la comunidad filosófica europea logró la masiva lectura hecha por Heidegger ${ }^{20}$. No hay duda de que con su enjundiosa obra acerca del autor del Zaratustra, Heidegger contribuyó enormemente a la recepción de Nietzsche, no solo en Alemania sino en el resto de Europa, entre otras razones, porque a diferencia de la mayoría de intérpretes anteriores fue uno de los primeros en reconocerle sin ambages su estatura como filósofo. Sin embargo, la reacción a la vez admirativa y negativa que la interpretación heideggeriana suscitó fue la que en buena medida desató una nueva ola de interés por Nietzsche, y la que promovió entre la joven generación de filósofos de los sesenta nuevas lecturas de su obra, las cuales, pese al largo trato que Francia tenía con Nietzsche, permiten hablar de un auténtico resurgimiento.

19 Cf. Jacques Le Rider, «Nietzsche, una pasión francesa. Cien años de recepción de Nietzsche en Francia», op. cit., 93.

20 El italiano Gianni Vattimo comparte la opinión de que efectivamente la lectura de Heidegger sirvió de catalizador para el resurgimiento de Nietzsche: «Sabemos que la publicación de los dos volúmenes de Heidegger sobre Nietzsche fue, si bien no el único, ciertamente sí un factor significativo en el renacimiento de Nietzsche. (...)». Gianni Vattimo, «Nietzsche, Heidegger's Interpreter», en Dialogue with Nietzsche (New York: Columbia University Press, 2005), 181. 
Ciertamente, si es posible hablar del resurgimiento de Nietzsche en los años sesenta es, en cierto modo, en un sentido negativo; en otras palabras, fue en contra de Heidegger que se buscó redescubrir a Nietzsche. Más exactamente, se quiso reivindicar al Nietzsche que, a juicio de estos nuevos y audaces lectores, desbordaba y ponía en jaque la lectura sistemática y, para algunos, profundamente dogmática elaborada por Heidegger. Esto no implica, empero, que se haya querido dar un paso atrás despojando a Nietzsche de su envergadura filosófica para devolverlo al terreno de la literatura y el arte. Antes bien, al reconocer en el suyo un pensamiento radicalmente revolucionario y, por lo mismo, refractario a todo tipo de clasificaciones y divisiones tradicionales entre géneros, era preciso rescatar lo que habría quedado invisible a la mirada de Heidegger. Deliberada o no, su miopía habría dejado por fuera de consideración el problema de la escritura en Nietzsche. Este es, sin duda, el punto que más reproches le merece y el que más echan de menos los nuevos intérpretes en la lectura hecha por Heidegger, pues es este precisamente el rasgo en el que advierten la expresión más clara de la radicalidad y novedad del pensamiento nietzscheano.

En este sentido resulta sobresaliente el ahora clásico ensayo de Maurice Blanchot titulado "Nietzsche y la escritura fragmentaria» ${ }^{21}$, en el que, teniendo seguramente en mente a Heidegger, el escritor francés defiende la posibilidad de una lectura sistemática de Nietzsche, pero advierte de manera contundente que una lectura de este tipo, hegelianizante, según la califica, no le hace verdadera justicia, pasando completamente por alto su auténtico y revolucionario alcance. En efecto, una lectura que pese a las discontinuidades, vacíos, saltos y contradicciones presentes en el discurso nietzscheano, encuentra la manera de atar los cabos, de superar y resolver dialécticamente las tensiones, en fin, de dar una interpretación de conjunto del pensamiento de Nietzsche, donde los fragmentos llegan a ensamblarse

21 Maurice Blanchot, «La escritura fragmentaria» en La ausencia del libro (Buenos Aires: Ediciones Caldén, 1973), 41-66. 
como partes de una totalidad, este tipo de lectura, afirma Blanchot, no solo es posible, sino también útil y necesario. No obstante, una lectura así, continua y conciliadora por principio, no agota lo que Nietzsche es capaz de decir, y, todavía más, no es la más relevante: «Existen dos hablas en Nietzsche» afirma Blanchot, y una lectura como la de Heidegger se revela completamente sorda a aquella de las dos que, por su capacidad para dar forma a un nuevo modo de pensamiento es la más importante de ambas: la fragmentaria.

La lectura de Blanchot hace parte de los trabajos que se presentaron en el célebre «Coloquio de Royaumont» de 1964. Este evento, en el que participaron además Foucault, Deleuze, Beaufret, Klossowski, entre otros, representa un hito sin par en la recepción reciente de Nietzsche en Francia y hasta puede ser tenido por el punto de quiebre que marca el inicio de su renovada vitalidad en ese país ${ }^{22}$. Se sumó a este el también memorable «Coloquio de CérisyLaSalle» celebrado algunos años después, en 1972, y cuyo tema era: «Nietzsche aujourd'hui?» (iNietzsche hoy?). Este encuentro contó particularmente con la participación de Deleuze, Derrida, Lyotard y Klossowski, quienes contribuyeron con varios escritos que desde entonces se han vuelto clásicos. La importancia alcanzada por estos eventos da prueba del renacer de Nietzsche en Francia, resurgimiento que en términos de Dominique Janicaud obedecía a «la preocupación común de releer a Nietzsche con ojos nuevos en la convicción compartida de que estas nuevas lecturas serían portadoras de porvenir» ${ }^{23}$. Ciertamente, en estas lecturas que se revelaron nuevas por la manera de leer a Nietzsche, parecía estarse jugando el porvenir de la filosofía francesa. En efecto, no solo se trató en ellas de leer a Nietzsche de modo distinto a como lo hiciera Heidegger, o a como lo hubieran hecho otros, sino, sobre todo, de leer de modo

El «Coloquio de Royaumont» es un evento académico internacional que tiene lugar anualmente en un castillo cerca de París. En 1964 particularmente sirvió de escenario para un memorable encuentro de filósofos franceses que expusieron allí sus lecturas de Nietzsche, convirtiéndose desde entonces en un capítulo inaugural del resurgir de Nietzsche en Francia.

23 Prefacio de Dominique Janicaud en Nouvelles lectures de Nietzsche, ed. Dominique Janicaud (Lausanne: Éditions l'Age d'Homme, 1985), 8. 
distinto a la tradición a partir de las «enseñanzas» de Nietzsche: «Leer: ahora medimos mejor, gracias a Nietzsche, en qué medida este "acto" no tiene nada de indiferente y hasta qué punto todo se juega allí», continúa Janicaud ${ }^{24}$.

Más recientemente, y pese a cierta reacción que a finales de los ochenta se generó en contra de la filosofía de Nietzsche, o más precisamente, en contra de los nietzscheanos franceses, no parece posible decir que la fascinación que Nietzsche ejerce en Francia haya declinado. Tal reacción negativa estuvo encabezada principalmente por Luc Ferry y Alain Renaut, quienes advirtieron como peligrosa la deriva hacia el antihumanismo que, según ellos, se habría tomado al pensamiento francés de los últimos años bajo la influencia de Nietzsche, pensamiento que denominan, no sin cierta ironía, «pensamiento del 68» ${ }^{25}$. En efecto, el propósito de estos autores es reivindicar la racionalidad y, en últimas, el proyecto moderno de la Ilustración que ellos ven amenazado por cuenta del nietzscheanismo francés. Para ello, sin embargo, reconocen que no pueden dar simplemente la espalda a Nietzsche, sino que más bien deben adoptar una estrategia que, por lo demás, y paradójicamente, parece de inspiración bastante nietzscheana: «pensar con Nietzsche en contra de Nietzsche ${ }^{26}$. De cualquier modo, y como prueba de la vigencia perenne de Nietzsche entre los franceses, basta ver el buen número de títulos que, según comenta Le Rider en el artículo señalado, han sido publicados en los últimos años ${ }^{27}$.

Ahora bien, si se quiere entender quién es ese «nuevo Nietzsche» que surge de las lecturas rebeldes hechas en Francia, lecturas que, en cierto modo, se dieron a la tarea de «salvarlo» del dogmatismo de Hei-

24 Ídem.

25 Jean-Luc Ferry y Alain Renaut, La pensée 68. Essai sur l'antihumanisme contemporain (Paris: Gallimard, 1985).

26 Jean-Luc Ferry y Alain Renaut (Eds.), Why we are NOT Nietzscheans? (Chicago/London: Chicago University Press, 1997).

27 Para un exhaustivo recuento de las publicaciones más importantes salidas en Francia acerca de la obra de Nietzsche en el último siglo, remítase el lector a: «Un siècle de réception française de l'oeuvre de Nietzsche (choix d'ouvrages et de quelques articles publiés en français, 1898-1999)» en Nietzsche. Le Cahier de L'Herne, ed. Marc Crépon (Paris: Cahiers de L'Herne, 2005), 296-302. 
degger, resulta necesario volver, aun cuando sea de manera sumaria, sobre los rasgos principales del Nietzsche de Heidegger, de tal modo que puedan verse mejor las razones del rechazo que esta lectura suscitó al punto de reorientar de manera radical la recepción de Nietzsche.

\title{
2. ¿Quién es el Nietzsche de Heidegger?
}

\begin{abstract}
«El Nietzsche de Heidegger no es el único o el último Nietzsche que tenemos. Tampoco es siempre el más ajustado, y difícilmente es el más simpático. La grandeza de una interpretación, sin embargo, no reside ni en la sutileza del especialista ni en la fidelidad del discípulo. Yace, más bien, en su habilidad para abrir un nuevo camino hacia su tema, y esto significa confrontar a aquellos de nosotros que quisiéramos seguirla, desafiarnos a encontrar nuestro propio camino hacia Nietzsche, y hacerlo libremente, críticamente» ${ }^{28}$.
\end{abstract}

¿Qué despertó el interés tan especial que Heidegger demostró por Nietzsche? Esta es, sin duda alguna, una pregunta insoslayable, en vista del estudio tan prolongado y sistemático que, como a ningún otro pensador, le dedicó Heidegger a Nietzsche. Por más de diez años, desde mediados de la década de los 30 hasta mediados de los 40, Heidegger le consagró a la filosofía de Nietzsche un número importante de cursos, de los cuales resultaron más de mil doscientas páginas escritas, reunidas luego en su célebre obra en dos volúmenes publicada en 1961 y traducida al francés diez años después ${ }^{29}$. Lo voluminoso de este trabajo es un dato que habla por sí solo de la importancia y, más aún, del desafío que seguramente Nietzsche suponía para su propia empresa filosófica. De hecho, Heidegger mismo puso este ejercicio interpretativo bajo el signo de una «confrontación» (Auseinandersetzung) de la que, al parecer, ni él mismo habría estado One, ed. Ashley Woodward (London/NY: Continuum, 2011).

29 Los cursos y ensayos que conforman las secciones de los dos tomos de Nietzsche publicados en 1961 son: (1936-37) «Voluntad de poder como arte»; (1937) «Eterno retorno de lo mismo»; (1939) «Voluntad de poder como conocimiento»; (1940) «Nihilismo europeo»; (1940) «La metafísica de Nietzsche» y (1944-46) «Nihilismo como determinado por la historia del Ser». Se destacan también los ensayos «La frase de Nietzsche: Dios ha muerto» (1943), «¿̇Qué significa pensar?» (1951) y «i̇Quién es el Zarathustra de Nietzsche?» (1953). 
convencido de haber salido bien librado, como dejaría entender, para algunos, su lapidario comentario de «Nietzsche me destruyós ${ }^{30}$. Seguramente, fue por cuenta de lo que para Heidegger estaba en juego en este cuerpo a cuerpo, que sin reserva alguna desplegó todos sus recursos en una lectura cuya fuerza innegable la convierte en una interpretación de la que ningún estudioso serio de Nietzsche puede en adelante prescindir, bien sea para asumirla, o bien, como hicieron muchos en Francia, para desmarcarse decididamente de ella.

En realidad, para Heidegger esta confrontación es en el fondo un ajuste de cuentas con la metafísica misma, en la medida en que Nietzsche es, a su juicio, el filósofo que resume la historia toda del pensamiento occidental: «Si en el pensamiento de Nietzsche la tradición previa del pensamiento occidental es reunida y completada respecto a algo decisivo, entonces la confrontación con Nietzsche se convierte en una confrontación con todo el pensamiento occidental hasta ahora» ${ }^{31}$. Ahora bien, no cabe duda de que la lectura que Heidegger realiza no es, ni pretende serlo tampoco, una lectura neutra, que aspirara como cualquier comentario escolar, a restituir de manera objetiva el conjunto de la obra de Nietzsche, contentándose con iluminar o enlazar algunos pasajes de comprensión particularmente difícil, para dar al final una mirada ajustada a las intenciones del autor. Heidegger no es un simple comentarista sino un filósofo que lee a otro filósofo desde su propia filosofía. En ese sentido, su lectura proyecta de entrada sus propios prejuicios, no con el ánimo, según aclara, de distorsionar lo que el otro, en este caso Nietzsche, ha dicho realmente, sino para desencubrir lo que a pesar suyo el autor no alcanzó a decir explícitamente. Heidegger, pues, lee a Nietzsche a espaldas suyas, pero no necesariamente pretende hacerlo en contra de él. Es por esto que frente a la reticencia que algunos pudieran expresar por el tipo de lectura que él realiza,

30 Nietzsche hat mir kaputt gemacht fue el comentario que, según declara Gadamer, le habría hecho su maestro, y que, como era de esperarse, ha recibido distintas lecturas según el «partido» que se quiera tomar en esta confrontación: para los nietzscheanos es el reconocimiento de una derrota filosófica, mientras que los fieles a Heidegger lo entienden más bien como un comentario simplemente relativo al agotamiento que le produjo un ejercicio tan arduo, pero finalmente, logrado de interpretación.

31 Martín Heidegger, «La voluntad de poder como arte», en Nietzsche, 125 años, ed. Pérez Mantilla, Ramón (Bogotá: Temis, 1977), 115. 
alegando que desconoce o que violenta el pensamiento de Nietzsche para ponerlo al servicio de su propia agenda, añadiendo sin empacho alguno lo que es de su propia cosecha pero que en Nietzsche mismo no aparece, Heidegger afirma lo siguiente:

\begin{abstract}
En el texto siguiente, exposición e interpretación están tan entrelazadas que no será claro en todas partes y de inmediato qué se extrae de las palabras de Nietzsche y qué se añade. Toda interpretación, sin embargo, no solo tiene que poder extraer del texto la cosa de que se trata, sino que, sin insistir en ello, inadvertidamente, tiene que poder agregar algo propio proveniente de su propia cosa. Este añadido es lo que el profano, midiéndolo respecto de lo que, sin interpretación, considera el contenido del texto, censura necesariamente como una intervención extraña y una arbitrariedad ${ }^{32}$.
\end{abstract}

En otras palabras, Heidegger se declara inmune ante cualquier acusación de arbitrariedad fundada en la idea, estéril para él, de que existe un sentido objetivo presente en el texto, al cual solo se puede acceder al precio de la completa autocensura. La suya no pretende ser una lectura objetiva o meramente reproductiva. Y, sin embargo, según pretende, puede ser considerada una lectura fiel si con ello se entiende que busca explicitar, no lo realmente dicho por el autor y presente para él, sino lo que, según Heidegger, tuvo que quedarle oculto al autor y que precisamente al encubrirse, le permitió con su ausencia pensar como efectivamente lo hizo. En otras palabras, busca sacar a flote lo que necesariamente debe pasar en silencio en lo que el autor sí dice. Su interpretación va entonces tras cierto motivo productivo que, según él, subyace a y hace posible ese discurso filosófico particular. Con todo y lo cuestionable que para muchos pueda ser esta forma de interpretar, que parece expropiar al autor de sus intenciones más explícitas (como se sabe, Nietzsche se declaró acérrimo crítico de la metafísica a la que se propuso superar), imponiéndole a la fuerza lo que no le pertenece, no admite duda el hecho de que Heidegger se las arregla para hacer una lectura particularmente incisiva y creativa de una obra que, más que ninguna otra escrita previamente, exige romper con hábitos de lectura e invita a encontrar paradigmas de interpretación diferentes a los tradicionales. 
En efecto, por diversas razones la escritura de Nietzsche resulta una suerte de enigma para sus lectores: su rechazo a la sistematicidad que lo lleva a proceder de forma «experimental» (Versuch), el gusto exacerbado por la contradicción, el recurso a géneros discursivos (poemas, aforismos, etc.) que no responden al tipo de argumentación habitual en filosofía, un estilo de escritura que vuelve borrosa la frontera con la literatura, etc. Haciendo honor al apelativo de «filósofo de las máscaras» con el que él mismo se auto-denomina, Nietzsche se complace en aparecer como un pensador refractario a cualquier intento de fijación bajo una doctrina definitiva, alguien que no tiene ningún problema en cambiar su punto de vista y en afirmar algo para luego negarlo ${ }^{33}$. Este rasgo de su pensamiento dio pie para que muchos lo desestimaran como un verdadero filósofo, reprochándole su incapacidad para elaborar un pensamiento sistemático y coherente. Todo ello contrasta, por otro lado, con la aparente transparencia de lo que escribe, ya que en cierto modo leer a Nietzsche es más fácil que leer a otros filósofos de la tradición, pero comprenderlo, en cambio, es una tarea mucho más difícil. El peligro está efectivamente en dejarse seducir por el tono personal y casi íntimo con el que Nietzsche se dirige a cada uno de sus lectores, fácilmente llamados a engaño acerca de su comprensión de un pensamiento que en realidad es extremadamente exigente. Consciente de ello, Heidegger advierte con prudencia: «Hay que aprender a leer a Nietzsche».

Ahora bien, como veíamos, Heidegger parece tener ganada de entrada una fórmula para abordar la compleja tarea de leer a Nietzsche. A diferencia de otros intérpretes que lo relegaron a la condición de poeta-filósofo, psicólogo, filósofo de la vida, crítico de la cultura,

33 Así describe, por ejemplo, James Winchester el desconcierto que suscita en el lector de Nietzsche la manera sinuosa y a la vez tan directa como este procede: «Incluso cuando 'escribe filosóficamente' e identifica claramente como suya una posición en el texto, Nietzsche confunde nuestras expectativas al hablar de manera más directa y personal de lo que normalmente es costumbre entre los filósofos. Tradicionalmente, los especialistas no están interesados en la visión de una persona, sino en la verdad hacia la cual se dirige. Con frecuencia Nietzsche subraya la parcialidad de sus puntos de vista. Y sus puntos de vista están sujetos a cambio». James Winchester, Nietzsche's aesthetic Turn. Reading Nietzsche after Heidegger, Deleuze, Derrida (Albany: suny Press, 1997), XI. 
etc., y que, amparados en ello, no lo tomaron muy en serio, Heidegger decide leerlo como filósofo, solo que decir esto tiene para él un significado muy preciso. Partiendo de su propia concepción de la metafísica como la «verdad del ser del ente», un pensador que merezca este título -y son raros esos genios, reconoce Heidegger-, es aquél que piensa al hilo de la pregunta por el Ser. Así pues, si Nietzsche ha de ser considerado seriamente, esto es, como un filósofo a título pleno, entonces debe ser leído, según Heidegger, como un pensador de esos que raramente surgen, y que en cuanto tal se plantea la única pregunta que cabe formularse y que lleva a pensar: la pregunta por el ser del ente. Así,

En cuanto designación del carácter fundamental de todo lo que es, la expresión ['voluntad de poder'] da una respuesta a la pregunta por qué es lo que es. Esta pregunta es desde la más remota antigüedad la pregunta propia de la filosofía. (...) eso significa que el pensamiento de Nietzsche se mueve dentro del largo camino de la pregunta directora de la filosofía: «¿̇Qué es el ente?»34.

Poco importa que Nietzsche no se haya planteado la pregunta explícitamente, ni que se haya declarado insistentemente enemigo de la metafísica, alérgico al concepto de Ser, al que considera una pura abstracción antropomórfica sin sustento en la realidad. Para Heidegger el pensamiento de Nietzsche debe ser visto como otro episodio, si bien el del desenlace definitivo, en la historia del ser; historia que es, en realidad, según lo había planteado en Ser y tiempo, la historia de su olvido. Así pues, a la pregunta por el ser del ente que, de acuerdo con Heidegger, Nietzsche se hace sin saberlo, este respondería, de nuevo según Heidegger, con el pensamiento de la voluntad de poder. Ahora bien, si Heidegger le concede tanta importancia a Nietzsche, esto es debido al lugar singular que para él ocupa en dicha historia de la metafísica: como decíamos antes, el lugar de su «consumación», entendido el término en la doble acepción de fin y de agotamiento. En otras palabras, con la «metafísica de la voluntad de poder» de Nietzsche, la meta- 
física occidental llegaría a su término a la vez que anuncia un más allá de la metafísica. Ciertamente, la metafísica de la subjetividad que según Heidegger se remonta hasta los griegos, se realiza con Nietzsche del modo más pleno, y, a la vez, consume, agotándolas, las últimas posibilidades del pensamiento metafísico.

Así pues, pese al propósito expreso de Nietzsche de querer demoler el platonismo, que para él resume esa larga historia del error que es la metafísica, error que consiste en postular un mundo suprasensible y verdadero bajo cuya sombra se sitúa un mundo sensible y aparente, Heidegger no duda en plantear que el pensamiento de Nietzsche es un "platonismo invertido» que en el fondo deja imperturbadas las bases de la metafísica. Hará así una lectura sistemática en la que mostrará que la metafísica de Nietzsche se sostiene en los temas fundamentales de «voluntad de poder», «eterno retorno de lo mismo», «nihilismo»y «superhombre», temas que para Heidegger no pueden ser cabalmente entendidos sino entrelazados unos con otros en una cadena inquebrantable de doctrinas amalgamadas. Efectivamente, a la pregunta por el ser del ente en cuanto tal, Nietzsche respondería, de acuerdo con Heidegger, con la «voluntad de poder», doctrina que bien entendida no podía sino conducirlo a su pensamiento central: el eterno retorno de lo mismo; uno y otro conforman un mismo pensamiento, sostiene Heidegger, en contra de quienes advierten una posible contradicción entre el movimiento infinitamente creciente de la voluntad, y el carácter circular del tiempo que parece sugerir la idea del eterno retorno de lo mismo. Aunque el eterno retorno es una idea que apenas sí aparece en sus escritos publicados, y a la que Nietzsche mismo no parece concederle una importancia determinante en el conjunto de su obra, para Heidegger, en cambio, constituye junto con la voluntad de poder la otra cara de una misma moneda, conformando entre ambas la respuesta central de Nietzsche a la pregunta metafísica por excelencia acerca del ser en cuanto tal en su totalidad. 
El nihilismo, por su parte, cuyo portavoz es el profeta Zaratustra, se revela como el rasgo esencial de la historia del pensamiento occidental que, transido desde siempre por un sentimiento de venganza contra el carácter efímero de la vida, no encontró otra salida más que renegar de la vida misma rebajándola como apariencia ante un «más allá» verdadero. Bien visto, el nihilismo no es solo un momento reciente de la historia en el que la caída de los valores supremos (evento que se resume en la sentencia «Dios ha muerto») da paso a la decadencia, sino que es el motor mismo de la historia que se fundó en esos valores ahora en crisis. Por esto, el nihilismo encuentra en el superhombre su realización más acabada, por cuanto este tipo de hombre, en pos del cual apunta Nietzsche, es capaz de renunciar gozosamente a cualquier absoluto y asumir plenamente la voluntad de poder como principio valorativo de todo cuanto puede ser tenido por él como un «ente». No hay pues fundamento alguno más allá de lo querido por la voluntad de poder. Es lo que lleva a Heidegger a afirmar que la metafísica de Nietzsche se mantiene en un subjetivismo.

No puede negarse que Heidegger lleva a cabo un ejercicio monumental al tratar de unir de manera sistemática y profundamente coherente las piezas que según él componen el rompecabezas de Nietzsche. Pero allí donde reside el mérito yace también el gran peligro de esta interpretación. Hasta los más desprevenidos lectores de Nietzsche se sorprenden y rechazan una lectura que lo muestra como el más acabado de los metafísicos. Levantan por ello sospechas las elecciones metodológicas que le permiten a Heidegger sostener esa conclusión ${ }^{35}$. Una de dichas elecciones fue la de concentrar su interpretación en la obra póstuma: Voluntad de poder. Causa problema, en primer lugar, porque con esta decisión Heidegger minimiza la importancia de las obras publicadas en vida por Nietzsche, que al haber contado con su supervisión directa permiten pensar que

35 Cf. Alan D. Schrift, «Heidegger reading Nietzsche», en Nietzsche and the question of interpretation. Between Hermeneutics and Deconstruction. Chapter 1 (London/NY: Routledge, 1990), 13-52. 
es en ellas donde él mismo veía realmente recogida su filosofía. En segundo lugar, porque esta pretendida obra póstuma de Nietzsche en realidad no lo era. Como a la postre lo puso al descubierto la investigación de Karl Schlechta, el amasijo de aforismos, notas, planes y numerosos fragmentos dispersos dejados por Nietzsche, no eran más que eso: una gran dispersión de apuntes sin unidad alguna, habiendo sido en realidad recogidos de forma malintencionada y abusiva por la hermana de Nietzsche, y hechas pasar por una obra inconclusa que nunca existió en la mente del filósofo ${ }^{36}$. Al margen de esta revelación que probablemente Heidegger no conoció sino tardíamente, él justificó su decisión de basarse en dicha «obra» afirmando que bajo la expresión de «voluntad de poder» Nietzsche expresaba la idea central de su pensamiento, y por lo tanto, era en una obra con ese título donde habría de encontrarse su filosofía más propia y acabada. Efectivamente, basado en la idea de que la doctrina de un pensador es lo que permanece impensado en lo pensado o dicho por él, Heidegger juzga la obra póstuma de Nietzsche como la expresión de su verdadera filosofía.

Por supuesto, muchas de las escogencias metodológicas de Heidegger obedecen al interés evidente de «metafisicalizar» a Nietzsche. El Nietzsche de Heidegger es pues, para responder a la pregunta de nuestro título, el último pensador del ser del ente, aquél en cuya filosofía se agotan las posibilidades de la metafísica y en quien se anuncia también un umbral de salida fuera de la metafísica, umbral que, por supuesto, no corresponde a Nietzsche sino a Heidegger traspasar. En efecto, para algunos críticos, toda esta movida interpre-

36 El ensayo de Karl Schlechta titulado «El caso Nietzsche» fue un trabajo decisivo en la recepción que a partir de allí se hizo de la Voluntad de poder, ya que el autor alemán demostró con lujo de detalles que esta «obra» no era tal, sino el resultado de una confección completamente sesgada, hecha por la hermana de Nietzsche, sirviéndose de notas y apuntes dispersos del filósofo que constituyen una yuxtaposición aleatoria de aforismos, y en ningún caso, como quisieron hacerlo ver la hermana y su ayudante, una obra unitaria y sistemática. Elisabeth Förster-Nietzsche no tuvo ningún escrúpulo en suprimir los comentarios de Nietzsche contra el antisemitismo y el nacionalismo alemán, así como una que otra observación en contra de ella, todo con el fin de hacer pasar a su hermano por un filósofo afín al nacionalsocialismo. Por supuesto, las implicaciones que el hallazgo de este fraude tiene para las interpretaciones de Nietzsche son de gran impacto, y en ese sentido, la interpretación de Heidegger no estaría exenta de cuestionamientos. Cf. Kart Schlechta, Le cas Nietzsche (Paris: Gallimard, 1960). 
tativa le resulta necesaria a Heidegger para poder defender mejor su propio proyecto como aquél que efectivamente abre la salida de la metafísica. Sería solo cuando el olvido en el que ha caído la pregunta por el Ser-pensado hasta ahora como ser de lo ente-comienza a ser pensado como tal olvido, que este puede ser superado y la metafísica llegar a su fin. Pero pensar este lugar, otro del ser, no es un destino que, según Heidegger, le hubiera correspondido a Nietzsche, aún preso en las redes de la metafísica.

Las anteriores son algunas de las razones que llevan a criticar el dogmatismo cerrado del que hace gala la lectura heideggeriana, la cual no parece dejar lugar para interpretaciones diferentes y más radicales del pensamiento de Nietzsche. Para muchos, efectivamente, más que un «buen Nietzsche», el Nietzsche de Heidegger parecía simplemente un «buen Heidegger». Pero, Nietzsche exigía que se lo leyera a él. En lugar de «asignarle un lugar fijado demasiado claramente en la historia de la metafísica, hay que leerlo escrupulosamente, en todos los sentidos, $a$ él, y no a los que pretenden clavarlo con un alfiler en el cuadro de las mariposas metafísicas ${ }^{37}$. Se reclamaban, pues, unas lecturas en las que se atendiera más a los gestos explícitos de su pensamiento, así como a otras preocupaciones suyas que solo forzadas o distorsionadas se dejan reducir al ámbito de la metafísica, tal como la entiende Heidegger ${ }^{38}$. Por eso puede entenderse que las lecturas francesas que dieron lugar al «nuevo Nietzsche» hayan buscado motivos para rescatar lo que en Nietzsche mismo se resistiría a la lectura de Heidegger y a su principio hermenéutico. Tales lecturas obligaron, por supuesto, a redefinir los rasgos esenciales de la filosofía de Nietzsche, pero igualmente, como advierte Gianni Vattimo, al responder críticamente a la apropiación hecha por Heidegger, también definieron la relación con la filosofía

37 Avant-Propos de Jean-François Balaudé, en Lectures de Nietzsche (Paris: Le Livre de Poche, 2000), 7-8.

38 Gianni Vattimo señala como punto crítico de la lectura hecha por Heidegger el que este haya desconocido tan abiertamente los aportes de Nietzsche en ámbitos como la crítica de la cultura, el psicoanálisis, la antropología, etc., reduciendo todo su pensamiento a la pregunta metafísica por el ser del ente. Cf. Gianni Vattimo, Introducción a Nietzsche (Barcelona: Península, 2001), 47-48. 
de este, de modo que puede decirse que un nuevo Nietzsche implicó a la par un nuevo Heidegger ${ }^{39}$.

\section{Un nuevo Nietzsche «à la française»}

La expresión «nuevo Nietzsche» se acuñó a partir de las lecturas provocadoras que diversos filósofos franceses hicieron de su obra desde finales de los años sesenta y durante la década de los setenta ${ }^{40}$. El resultado es un Nietzsche que, a diferencia del de Heidegger, se muestra refractario a cualquier tentación de reducir su filosofía a significados últimos. Uno que, por ende, no es uno, sino varios. Efectivamente, buscando estar a la altura de su carácter elusivo, de sus múltiples máscaras, de la infinitud de interpretaciones que él mismo reivindica, estas lecturas se nutren de la irreducible pluralidad de sentidos de sus textos. No es fácil entonces afirmar que existe una línea interpretativa claramente definida desde la cual se haya querido salir al paso a la lectura sistemática y totalizadora hecha por Heidegger. A decir verdad, llama la atención que muchas de las nuevas lecturas de Nietzsche no se hayan propuesto controvertir o refutar

39 Efectivamente, para el filósofo italiano Gianni Vattimo, en esas nuevas lecturas de Nietzsche no se trata solo de reivindicar a Nietzsche, sino de la relación que Heidegger guarda con él, y al revés. Si Nietzsche renació en estas lecturas no fue para dejar atrás a Heidegger (para depurarlo de los excesos de este o algo así), sino en buena medida, también para dar mejor cuenta de la filosofía de Heidegger, particularmente la de su último período. Para Vattimo la relación entre Heidegger-Nietzsche no es un problema más de los varios que han dominado el debate filosófico de las últimas décadas en el continente europeo, sino que, a su juicio, constituye «el» problema central de la filosofía de hoy, aquél en el que, podríamos decir, se juega su futuro. Así pues, del mismo modo como se habla de un «nuevo Nietzsche» en buena cuenta por las lecturas que buscan preservarlo de Heidegger, también se dice que hay un «nuevo Heidegger», y quizás mucho de este renacer tendría que ver, si seguimos al filósofo italiano, con la influencia que a pesar suyo Nietzsche habría tenido sobre él y su famoso giro (Kehre). Al respecto conviene citar las siguientes líneas: «Durante los últimos veinticinco años la filosofía continental ha estado girando en torno a la discusión de dos tópicos: el significado del pensamiento de Nietzsche, estudios de los cuales hubo muchos muy agudos en Europa a comienzos de los sesenta junto con nueva investigación filológica de sus textos, y la filosofía del "último Heidegger" que también se volvió ampliamente conocida hacia el final de los cincuenta. El interés en el último Heidegger y el renacimiento de Nietzsche no son simplemente dos acontecimientos filosóficos que casualmente coinciden en el tiempo. (...) Aunque el renacimiento de Nietzsche comprende trabajo filológico estrictamente independiente de los problemas de interpretación que Heidegger pone de presente, por todas partes ese renacimiento se traslapa con la revitalización del interés por el último Heidegger». Gianni Vattimo, «Nietzsche, Heidegger's Interpreter», op. cit., 181-182.

40 Ver David Allison (Ed.), The New Nietzsche. Contemporary styles of interpretation (Boston, Massachussets: MIT Press, 1999). 
frontal y explícitamente las premisas o las conclusiones de la lectura heideggeriana, en cuyo caso esta sería el punto de intersección hacia el cual se las vería converger. Más bien, lo que destaca en ellas es el interés por leer a Nietzsche desde una concepción completamente distinta de la lectura: leer a Nietzsche como él lo exige, supondría dejar de perseguir el sentido oculto tras lo dicho, para hacer del decir mismo y de su forma de ocultar, el gesto al que debe prestarse oído. Así pues, aunque no existe un núcleo de temas en torno a los cuales se pongan en discusión, parece posible identificar en medio de la diversidad de interpretaciones un tema alrededor del cual poner a dialogar a muchos de los nuevos intérpretes, en la medida en que para un buen número de ellos este constituye un asunto vital en la comprensión de Nietzsche: la cuestión del estilo ${ }^{41}$.

Si respecto a Nietzsche la reflexión acerca de su estilo adquiere un peso esencial, esto es porque el término denota aquí la relación indisociable que en él guarda el contenido de su pensamiento con su forma de exponerlo. Ciertamente, no es un aspecto secundario o exterior a su pensamiento el que se exprese del modo como lo hace: en aforismos, poemas, cartas, ensayos, etc., sino que es parte constitutiva de él. Para ponerlo en otros términos, el estilo de Nietzsche tiene por sí mismo significado filosófico. Por esto, la convicción de muchos de estos nuevos lectores es que cualquier lectura interpretativa de Nietzsche que quiera hacer justicia a lo singular y radical de su pensamiento tiene necesariamente que vérselas con la cuestión del estilo (o más bien, los estilos) de escritura en Nietzsche. Cuestión que, sin embargo, no pareció retener de manera particular la atención de Heidegger, quien en su lectura sistemática y totalizante del pensamiento nietzscheano prescinde de cualquier consideración acerca de las formas que emplea para expresarlo. De modo que atender al estilo nietzscheano, como pretenden hacerlo estas lecturas, implica renunciar a la tentación de plegar su pensamiento bajo cualquier

41 Ver Alan D. Schrift, «The French Scene» En Nietzsche and the question of interpretation. Between Hermeneutics and Deconstruction. Chapter 3 (NY: Routledge, 1990), 77-94. 
divisa de unidad o de identidad de sentido que desconozca sus múltiples estrategias de escritura.

Ahora bien, al referirnos a estas nuevas lecturas de Nietzsche conviene tener presente la distinción que Alan Schrift traza cuando afirma que unas se inspiraron en Nietzsche para pensar con él, mientras otras, por su parte, lo pensaron $a$ él. Es lo que también sugiere Savater cuando afirma que hubo quienes escribieron sobre su obra y, por otro lado, los que escribieron a partir de ella ${ }^{42}$. Así pues, habría, por un lado, los que avanzando de la mano de Nietzsche, pero a la vez dejándolo de lado -en tanto no adoptaron necesariamente los mismos temas de reflexión-, inauguraron una manera o modo propios de pensar, si bien à la Nietzsche. Por otro lado, estarían los que, aun cuando acentuaron aspectos todavía inéditos de los textos, ayudando con esto a ampliar el horizonte temático de la recepción, puede decirse que en el fondo se contentaron con comentar la obra de Nietzsche. Entre los segundos podría destacarse, por ejemplo, Sarah Kofman con su muy célebre Nietzsche y la metáfora $(1964)^{43}$, trabajo que dejó profunda huella por su manera de leer la filosofía de Nietzsche al hilo de las metáforas más sobresalientes presentes en sus obras. Se cuentan también en este grupo Eric Blondel, Maurice Blanchot y Bernard Pautrat, para no mencionar sino algunos de quienes realizaron significativos trabajos de interpretación en los que se da cuenta del interés creciente que despertaba el carácter singular de su escritura como la verdadera puerta de entrada a su

«Las obras que en Francia y España se han producido según la experiencia de leer a Nietzsche como revulsivo, poco tienen que ver con las descripciones tradicionales del "sistema" nietzscheano; escritas siempre no sobre, sino a partir de Nietzsche, tratan fundamentalmente de suponer una ruptura con la expresión de la razón, tal como funciona hasta el comienzo de la posguerra en el pensamiento europeo contemporáneo». Fernando Savater, Así hablaba Nietzsche (Barcelona: Áltera, 1973), 21. Muy a tono con los antinietzscheanos franceses, como Ferry y Renaut, Savater continúa con cierto tono reprobatorio comentando el curso dogmático que según él habría adoptado esta nueva recepción de Nietzsche en Francia, que si bien fue inicialmente novedosa, terminó, según el español, convertida en un nuevo credo o dogma que anuló a la postre el potencial subversivo de Nietzsche al convertirlo en un ídolo más de adoración: «(...)Hoy evidentemente, comienza ya a funcionar, al menos en Francia, una esclerotizada jerga neonietzscheana, y pululan obritas de epígonos cada vez más deficientes. Amenaza un academicismo de puertas afuera; el pensamiento que no quiera instalarse en él tendrá que seguir buscando campos de lucha para su expresión». Ibíd., 21. 
filosofía. Ahora bien, entre los primeros, es decir, los que inspirados por Nietzsche iniciaron una filosofía propia y novedosa, se contarían, precisamente, los llamados filósofos de la diferencia: Derrida, Deleuze, Foucault y Lyotard, principalmente.

Sin embargo, hay que reconocer que no siempre resulta fácil establecer una distinción tan tajante entre las que serían unas lecturas productivas y otras, si se quiere, más bien reproductivas de la obra de Nietzsche. Gilles Deleuze, por ejemplo, con su libro Nietzsche y la filosofía publicado en $1962^{44}$, marcó un hito en la nueva recepción del filósofo alemán en Francia. Hay que anotar que en el momento en que el autor del Anti-Edipo decidió ocuparse de Nietzsche dominaba todavía en el ámbito académico el canon de autores que había sido referencia obligada para las generaciones anteriores, en particular las llamadas tres $\mathrm{Hs}$, de tal modo que su gesto fue percibido como cargado de una buena dosis de rebeldía, lo que, visto retrospectivamente, anunciaba indudablemente el camino heterodoxo que su autor iría tomando de forma cada vez más decidida en sus posteriores trabajos conjuntos con el psicoanalista Félix Guattari. En cualquier caso, se trataba en ese libro de hacer un comentario o un estudio crítico, al estilo de los que Deleuze realizaría también sobre Hume, Kant o Spinoza, trabajos que aparentemente corresponden al tipo de monografías que se realizan en el campo de la historia de la filosofía. Sin embargo, la lectura deleuziana no solo fue un comentario que sacó a relucir aspectos inéditos de la filosofía de Nietzsche, sino que revelaba ya un modo de pensar propio de Deleuze. En otras palabras, el Nietzsche de Deleuze no solo pretendía ser un «buen Nietzsche» sino que era también ya un «buen Deleuze» en ciernes. Ciertamente, en sus trabajos sobre otros autores resulta siempre extremadamente difícil separar con nitidez lo que dice Deleuze de lo que dice el filósofo del que se ocupa, ocurriendo en realidad lo que él mismo describe como una suerte de procreación nacida de ambos.

44 Gilles Deleuze, Nietzsche y la filosofía (Barcelona: Anagrama, 2002). 
Resulta imposible detenerse aquí en los detalles de la laboriosa interpretación deleuziana, pero se puede decir que mucho de su resonancia se debió a la novedosa manera de entender la relación entre las fuerzas activas y las fuerzas reactivas de las que habla Nietzsche. En la medida en que una fuerza es en realidad el resultado de la diferencia de fuerzas, en sentido estricto nunca hay una sino múltiples fuerzas en juego, cada una buscando imponerse sobre las demás. Esto permite hablar a Deleuze de la fuerza en Nietzsche como siendo en últimas "diferencia», la cual no es solo diferencia en cantidad sino también en calidad. Entre las fuerzas en pugna habría, según el francés, no solo diferencias cuantitativas que explican que unas se impongan sobre otras, sino que habría, cualitativamente hablando, diferencias entre fuerzas activas, es decir, las que se autoafirman antes de negar a otras, y fuerzas reactivas, es decir, las que se afirman mediante su negación de otras. De modo que aun si cuantitativamente unas fuerzas pueden someter a otras, no siempre las que someten son cualitativamente superiores a las sometidas, como lo denuncia el mismo Nietzsche cuando en su crítica a la moral cristiana habla de la necesidad de proteger a los fuertes de los débiles, no obstante ser estos últimos más numerosos que los primeros. Para Deleuze, entonces, la voluntad de poder es siempre diferencial, esto es, una relación cambiante y dinámica de fuerzas plurales, imposibles de ser reducidas a unidad o totalidad alguna. Ciertamente, en donde se advierte con mayor claridad la influencia de Nietzsche es sin duda en la ontología de Deleuze. En Diferencia y repetición (1969), considerada por muchos como una de las obras capitales del autor e incluso una de las más representativas del siglo xx, Deleuze desarrolla su intuición ontológica fundamental acerca de que el ser se dice es del devenir. Para Deleuze, efectivamente, lo que es, es movimiento, cambio, en últimas, diferencia, por lo que, en últimas, lo único que según él se repite es paradójicamente lo irrepetible, esto es, la diferencia pura. Lo que retorna eternamente no es lo mismo sino la diferencia radical. Deleuze ve así en Nietzsche al contradictor más potente de Hegel y, en ese sentido, opone la unidad de la síntesis hegeliana a la afirmación gozosa de la multiplicidad que encuentra en Nietzsche. 
En cuanto a Jacques Derrida, no hay duda de que fue uno de los que más contribuyó al resurgimiento de Nietzsche en Francia, y quizás quien de manera más explícita tomó distancia de la lectura de Heidegger, no dejando por ello de reconocerle sus innegables méritos. En su reconocido libro Espolones. Los estilos de Nietzsche ${ }^{45}$ (1972), Derrida pone en cuestión el principio totalizador que rige la lectura hermenéutica de Heidegger, según el cual hay significados últimos y definitivos que subyacen al texto nietzscheano. Derrida llama puntualmente la atención sobre la inexplicable indiferencia que Heidegger demuestra ante la metáfora, varias veces empleada por Nietzsche, y presente en el célebre fragmento titulado «De cómo el mundo verdadero terminó convertido en fábula», en la que el filósofo alemán asocia la verdad con la mujer. Sorprende que Heidegger, quien se ocupa detalladamente de este fragmento, no diga sin embargo ni una sola palabra al respecto, decisión que a la larga dejaría ver, según Derrida, que su manera de leer no hace del todo justicia a Nietzsche, pues pasa por alto la imposibilidad estructural de decidirse

"Nuestra imagen del "nuevo Nietzsche" tal como ha surgido desde finales de los sesenta encuentra su expresión más sugestiva en los escritos de Jacques Derrida. Nietzsche, tal como lo ha explorado Derrida, ofrece una nueva clase de comunicación, una que resiste la tentación de establecer doctrinas fijas o significados últimos, pero persiste en el desciframiento infinito de sus propios términos. Derrida ilumina el giro de Nietzsche hacia la interpretación infinita, o la afirmación de una visión del mundo como juego, y muestra cómo el estilo en el cual ese pensamiento se manifiesta debe ser plural. Y con su insistencia en estas actitudes, Derrida necesariamente desafía la interpretación que Heidegger hace de Nietzsche como el pensador de la noción más condensada de la metafísica moderna, la "voluntad de poder". (...) En realidad, Derrida confronta a Heidegger en cada uno de sus escritos, y la confrontación está siempre, directa o indirectamente, ligada con Nietzsche». Ernst Behler, Confrontations. Derrida/Heidegger/Nietzsche, (Stanford: Stanford University Press, 1991), 49. Esta última afirmación de Behler es bastante relevante, pues, a fin de cuentas, el autor considera que pese al vínculo tan fuerte que une a Derrida con Heidegger, el punto de quiebre entre ambos está en la manera tan diferente como cada uno lee a Nietzsche. En otras palabras, si Derrida no es una simple prolongación de Heidegger -como algunos pretenden-, esto tiene que ver fundamentalmente con el rechazo de Derrida a asumir la lectura heideggeriana de Nietzsche, o, también podría decirse, está en su convicción de que pese a todo, Nietzsche es más radical que Heidegger en su crítica a la metafísica. En el célebre encuentro sostenido por Derrida y Gadamer en 1991, el filósofo de Heidelberg situó la razón del fracaso en su diálogo con Derrida en la que él consideró cierta fascinación desmedida de los franceses por Nietzsche. Hay que decir que Gadamer asume plenamente la lectura de Heidegger sobre Nietzsche como el último de los filósofos de la historia del olvido del ser: «Echo de menos en los seguidores franceses de Nietzsche un esclarecimiento de lo que significa la dimensión seductora del pensamiento nietzscheano. Solo así llegan a pensar, creo yo, que la experiencia del ser que Heidegger intentó descubrir detrás de la metafísica es la más radical en el extremismo de Nietzsche». Hans-Georg Gadamer, «Texto e interpretación», en Verdad y método, Tomo II (Salamanca: Sígueme, 1992), 322-323. 
por un sentido último, debiendo dejar sus textos irremisiblemente abiertos. En efecto, contrariamente a cierta opinión difundida acerca de la patente misoginia de Nietzsche, Derrida muestra el carácter indecidible del término «mujer» en sus textos, en la medida en que tras dicho término lo que se oculta es una oposición entre «verdad» y «no-verdad» que no se deja resolver dialécticamente a favor de ninguno de los dos sentidos contrapuestos. Con todo, la imposibilidad de llegar a una última palabra acerca del valor a darle al signo «mujer», su puesta en suspenso, es la que precisamente hace legible el texto nietzscheano en su apertura.

Una lectura así se entrega sin complejos al juego libre de la escritura que, según Derrida, remite infinitamente de unos signos a otros sin llegar a fijar un significado trascendental que desde fuera del juego de la significación lo ordenara y le pusiera término. De hecho, si nos atenemos a la distinción que Derrida establece entre dos maneras de entender la interpretación ${ }^{46}$, la una grave y la otra lúdica, podría decirse que la de Heidegger adolece de la gravedad de la primera, al entender la interpretación como un desciframiento que no puede proceder sin clausurar el sentido del texto, imponiéndole por la fuerza un límite exterior al juego de diferencias que lo constituye. En la medida en que en un texto cada signo significa no por sí mismo, sino por sus diferencias con los demás, la escritura es pura producción de diferencias (lo que Derrida busca expresar con su neologismo de «différance»). La interpretación que, por ende, se entiende lúdicamente como un librarse productivo y gozoso al juego infinito de la escritura, implica, precisamente, la desarticulación de toda ilusión de un sentido o de un centro presente e idéntico a sí, trascendente al texto, en torno del cual pareciera gravitar el juego de diferencias. Afirmar tal centro,

46 Derrida escribe: «Hay, pues, dos interpretaciones de la interpretación (...) Una busca descifrar, sueña con descifrar una verdad o un origen que escapa al juego y al orden del signo, y vive como un exilio la necesidad de interpretación. La otra, que no está vuelta hacia el origen, afirma el juego e intenta pasar más allá del hombre y del humanismo, siendo el nombre del hombre el nombre de ese ser que, a lo largo de la historia de la metafísica o de la onto-teología, es decir, de toda su historia, ha soñado con una presencia plena con un fundamento seguro, origen y fin del juego». Jacques Derrida, «La structure, le signe et le jeu», en L'Écriture et la Différence (Paris: PUF, 1967), 427. 
dice Derrida, no es sino otra manera de mantenerse atado al valor fundamental de la metafísica: la «presencia plena» o ousía. Así pues, la deconstrucción de la «metafísica de la presencia», tal como Derrida describe el motivo de su empresa filosófica, comporta un rechazo a la ingenuidad de pensar un afuera absoluto de la metafísica, y llama más bien a buscar dicha "salida» al interior del sistema de pensamiento metafísico, si bien se trata de permanecer en él de un modo estratégicamente subversivo y marginal. Según Derrida, y en acuerdo con Nietzsche, es inevitable moverse dentro del sistema binario oposicional que caracteriza el pensamiento metafísico, pero es preciso hacerlo de manera oblicua y tangencial para poder entrabarlo. La deconstrucción pasa así por identificar las oposiciones estructurales a cualquier discurso, por desenmascarar la jerarquía que las gobierna otorgando a uno de los términos opuestos el valor superior de la presencia, por invertirla, y finalmente por imposibilitar la oposición dentro de una nueva economía textual. Esta manera de interpretar, que desmonta sistemáticamente toda ilusión de un sentido pleno e idéntico, tiene una gran deuda con la forma como Nietzsche mismo entendía la crítica a la metafísica como superación de su pensamiento oposicional, y es precisamente el tipo de lectura que Derrida opone, en su interpretación de Nietzsche, a la lectura de Heidegger.

Por su parte, Michel Foucault no tiene problema en declararse abierta y completamente nietzscheano ${ }^{47}$. Para comenzar, su estrecha filiación tiene que ver con la adopción en su propia investigación del método genealógico, el cual tiene, a la manera de Nietzsche, el propósito de desentrañar las condiciones que históricamente hicieron posible el surgimiento de ciertos conceptos y discursos a partir de los cuales nos comprendemos en el presente, y que, olvidadizos de ese origen casual y contingente, hemos terminado por erigir en verdades absolutas e incontestables. De allí que el trabajo genealógico

47 «Je suis simplement nietzschéen»: así se declaraba Foucault, de modo tajante, en Les Nouvelles Littéraires (1984). Citado por François Dosse, Histoire du structuralisme, Vol. 1. (Paris: La Découverte, 1992), 432. 
no tenga para Foucault un interés simplemente historiográfico, sino que, como también lo concebía Nietzsche, busque liberarnos de una relación dogmática y asfixiante con la historia, abriendo perspectivas para un nuevo porvenir ${ }^{48}$. Si en algo interesa, pues, saber cómo hemos llegado a ser lo que hoy somos, es en la medida en que este ejercicio reconstructivo nos libera para destruir cualquier identidad impuesta como natural y originaria, y para dejar la puerta abierta a otros modos posibles de ser.

De otro lado, la deuda de Foucault con Nietzsche se advierte claramente en la manera como el francés desarrolla el tema del poder, cuya crítica atraviesa como hilo conductor buena parte de su prolija obra. Tomando distancia de la tradicional concepción político-jurídica que entiende el poder como propiedad o potestad de un sujeto o estado soberano, así como de la hipótesis que él llama «represiva», según la cual el poder se ejerce exclusivamente de manera negativa para reprimir o limitar la acción de otros, Foucault entiende el poder, en consonancia con Nietzsche, como un juego de fuerzas esencialmente productivo y dinámico, fluyendo sin centro fijo por una red de relaciones en la que todos los individuos estamos inevitablemente implicados de diversas maneras. Es lo que vuelve tan difícil, pero a la vez tan necesaria, la tarea de resistir a los silenciosos efectos del poder, en particular en lo que respecta a sus estrategias de dominación de los individuos mediante la subjetivación. Foucault llegaría a declarar que a lo largo de su obra habría estado movido por el interés de desenmascarar los mecanismos que desde la modernidad han moldeado de forma violenta la manera como nos concebimos a nosotros mismos como sujetos. No hay duda de que la crítica demoledora de Nietzsche al concepto moderno de sujeto encontró en Foucault una continuación bastante fiel.

Por último, de los llamados filósofos de la diferencia es quizás respecto de Jean-François Lyotard del que puede decirse que no guarda una deuda directa con Nietzsche. Más evidentes parecen ser 
sus lazos con Kant, Wittgenstein, o incluso Levinas. Con todo, cabe decir que el padre de la posmodernidad tampoco pareció escapar por completo a la influencia del filósofo alemán, habiendo pasado, según algunos comentaristas, por un momento nietzscheano, no siempre bien apreciado ${ }^{49}$. Dicha influencia tendría que ver con la afirmación que hace, a la manera de Nietzsche, de infinitas interpretaciones y, por ende, con su rechazo ante cualquier intención de erigir una de ellas como la más verdadera. En efecto, según Lyotard, los metarrelatos que desde la modernidad pretenden organizar y dictar por anticipado el sentido a los diversos relatos particulares, están llamados a perecer. Es precisamente en la ausencia de un criterio absoluto de validez que radica la bautizada por él «condición posmoderna». Pero lejos de ser un motivo de lamentación, la pérdida de valor de tales metarrelatos constituye para Lyotard un evento prometedor, en la medida en que ha sido al precio de una gran injusticia que se ha pretendido poder traducir los distintos juegos de lenguaje -o interpretaciones según diría Nietzsche-, a uno más universal y abarcador en el que pudieran resolverse todos los desacuerdos particulares. La diferencia (différend), en el sentido radical que le da Lyotard, ocurre allí donde lo que busca ser dicho por alguna de las partes en conflicto escapa a toda formulación posible, y esto no en razón de una incompetencia lingüística por parte de quien reclama, sino por cuenta de las reglas de juego del lenguaje imperante, que al ser erigido como el único lenguaje en el que se permite a la víctima expresar su daño, la silencia de entrada. Así pues, antes que ignorar o simplificar las diferencias, se trata, según Lyotard, de visibilizarlas. En lugar de construir grandes relatos con vocación universal y homogenizante, la tarea de la filosofía es defender la multiplicidad de los pequeños relatos (petit récits).

En resumen, ya fuera para explicarlo desde nuevas perspectivas filológicas, o bien para utilizarlo como plataforma hacia proyectos

49 En su muy ilustrativo libro sobre la herencia de Nietzsche en el post-estructuralismo francés, Alan Schrift comenta lo siguiente: «Este momento nietzscheano ha sido ignorado por la mayoría de los intérpretes de Lyotard. Peter Dews, por ejemplo, ve en "Solo un juego" una ruptura crucial con el nietzscheanismo de los setenta». Alan Schrift, Nietzsche's French Legacy. A Genealogy of Poststructuralism, op. cit., 106. 
filosóficos propios y originales, no cabe duda de que en el encuentro que tiene lugar en contra de la lectura de Heidegger, entre los nuevos lectores franceses y Nietzsche, un rasgo esencial al «nuevo Nietzsche» se destaca: se trata de su resistencia a ser domesticado bajo una lectura que privilegie la totalidad o la unidad de sentido; en otras palabras, su irreducible pluralidad. Para leer $a$ Nietzsche, parecen haber comprendido estos nuevos lectores, es preciso leer como Nietzsche, lo cual quiere decir, producir y celebrar infinitas lecturas posibles.

\section{Pensar la diferencia}

Resta todavía por formular una última pregunta. Es acerca de la razón por la que estos nuevos Nietzsche franceses se ocupan de modo tan apremiante en pensar la diferencia, creando para ello expedientes conceptuales completamente nuevos. En efecto, estas filosofías parecen unirse, si bien no entre ellas directamente, sí en contra de un enemigo común ${ }^{50}$ : el pensamiento que no piensa la diferencia en cuanto que verdadera diferencia, esto es, que no la piensa radicalmente como una diferencia irreducible a cualquier identidad. El enemigo es un modo de pensar que se distingue por la «decisión» filosóficamente cuestionable de concebir la diferencia como esencialmente subordinada a lo idéntico; es decir, que la entiende como un accidente externo y secundario de este. Si esta decisión urge una corrección es por la convicción de que ella ha

50 «¿QQuién es el enemigo [de estas filosofías]? Las filosofías del estado, las que dan crédito a la unidad, la identidad; las que pueden ser absorbidas bajo menciones tan generales como "metafísica occidental", las que apuntan a hacer fracasar la diferencia y la diseminación en provecho de los sistemas. Allí se ubican no solamente las filosofías reducidas a sus formas más simples con el fin de rechazarlas, como las fenomenologías, sino igualmente las filosofías de las que se sospecha que sirvan de garante a un orden establecido bajo la figura de un legislador del Estado. Por la vía del sentido, del ser, del estado o de la dialéctica, ellas atribuirían a la filosofía un rol de subordinación de todo lo aleatorio a la identidad, redoblada por mecanismos de monopolización sociopolíticos. Se puede decir así: estas filosofías pretenden unificar lo que se contentan con someter. Violentan lo heterogéneo al punto de imponer por todos lados el nombre de lo uno. (...) La disposición fundamental [de las filosofías de la diferencia] consiste en ceder la palabra a formas extremas del lenguaje y del comportamiento, aparentemente reducidas al silencio por el orden del Sistema (del Saber y del Estado): la locura, lo marginal, la exclusión, la disidencia o, más ampliamente: la diferencia». Christian Ruby, Les Archipels de la Différence. Foucault-Derrida-Deleuze-Lyotard (Paris: Éditions du Félin, 1989), 10. 
provocado inevitables y nefastas consecuencias en el orden de lo político, lo ético y lo social. El totalitarismo o la Shoah, por ejemplo, no pueden ser considerados simples accidentes, si bien muy graves, en el curso de la historia occidental. No son desvíos lamentables del hasta entonces seguro camino de progreso y emancipación emprendido desde la modernidad, sino que tales acontecimientos $-\mathrm{y}$ otros igualmente dolorosos aunque quizás menos visibles (esclavitud, colonización, régimen poscolonial, etc.)-, se revelan para estas nuevas filosofías como una consecuencia directa de cierto modo de pensar el ser y el hombre que domina desde antiguo, y que alimentó tales proyectos de progreso y emancipación. Un modo de pensar dogmático que ha hecho de la diferencia su punto ciego. Por tal razón, repensar la diferencia fuera de ese esquema represivo y sistemático que la reduce a ser una forma secundaria de la identidad o la totalidad, supondría cerrar la posibilidad para que eventos similares de exclusión, aniquilación, ocultamiento, etc. sigan ocurriendo.

Así pues, si la cuestión de la diferencia ha animado buena parte de la filosofía francesa de los últimos 50 años, es porque esta se ha dado a la tarea de abrir el pensamiento a lo otro y a la multiplicidad y, más precisamente, porque ha emprendido la búsqueda de un espacio para pensar modos de ser y de vivir que no solo difieren del modo occidental, sino que, sobre todo, lo ponen radicalmente en cuestión. Esto ha conducido a formas de filosofar que privilegian la categoría de la diferencia en contra de aquellas, típicamente metafísicas, de lo uno, lo mismo, lo idéntico. Y aunque en parte por esta razón no es posible reunir bajo una divisa común a los autores asociados con esta denominación, ya que sus planteamientos resisten ser agrupados en una misma corriente -hablar de "escuela posmoderna» o "post-estructuralista» es apenas un gesto operacional para sus detractores-, no es del todo equivocada la impresión acerca de que sus obras tejen algo así como una red conceptual y problemática, o, al menos, que respiran un «aire común». Los autores que señalamos, que configuran este singular panorama filosófico a la vez tan innovador y difícil, asumieron el desafío de pensar lo «impensado», el 
«afuera», el «revés» o lo "otro» de la filosofía, desde el único lugar desde el cual, paradójicamente, es posible hacerlo, a saber: desde la filosofía misma. Y en esa empresa fue Nietzsche quien al parecer les brindó los recursos más eficaces para hacerlo.

\section{Bibliografía}

Allison, David. The New Nietzsche. Contemporary styles of interpretation. Boston: мIT Press, 1985.

Behler, Ernst. «Nietzsche in the twentieth century». En Cambridge Companion to Nietzsche, editado por Bernd Magnus y Kathleen Higgins, 281-322. Cambridge: Cambridge University Press, 1996. . Confrontations. Derrida/Heidegger/Nietzsche. Stanford: Stanford University Press, 1991.

Blanchot, Maurice. «La escritura fragmentaria». En La ausencia del libro, 41-66. Buenos Aires: Ediciones Caldén, 1973.

Campioni, Giuliano. Les lectures françaises de Nietzsche. Paris: PUF, 2001.

Crépon, Marc. (Ed). Nietzsche. Le Cahier de L'Herne. Paris: Les Cahiers de l'Herne, 2005.

Dastur, Françoise. Philosophie et différence. Paris: Éditions de la transparence, 2004.

Deleuze, Gilles. Nietzsche y la filosofía. Barcelona: Anagrama, 2002.

Derrida, Jacques. Espolones. Los estilos de Nietzsche. Valencia: PreTextos, 1998.

Descombes, Vincent. Lo mismo y lo otro. Cuarenta y cinco años de filosofía francesa (1933-1978). Madrid: Cátedra, 1998.

Dosse, François. Histoire du structuralisme. 2 Vols. Paris: Éditions La Découverte, 1992.

Ferry, Jean-Luc, y Renaut, Alain. La pensée 68. Essai sur l'antihumanisme contemporain. Paris: Gallimard, 1985. 
Ferry, Jean-Luc, y Renaut, Alain, (Eds.). Why we are NOT Nietzscheans? Chicago/London: Chicago University Press, 1997.

Foucault, Michel. Nietzsche, la genealogía, la historia. Valencia: Pre-Textos, 2000.

Hamacher, Werner. (Hgrs.) Nietzsche aus Frankreich. Essays von Maurice Blanchot, Jacques Derrida, Pierre Klossowski, Philippe Lacoue-Labarthe, Jean-Luc Nancy und Bernard Pautrat. Frankfurt/M/Berlin: Ullstein, 1986.

Heidegger, Martin. Nietzsche. 2 Vols. Barcelona: Destino, 2000.

Janicaud, Dominique. (Ed.) Nouvelles lectures de Nietzsche. Lausanne: Éditions l'Age d'Homme, 1985.

Kaufmann, Walter. Nietzsche. Philosopher, Psychologist, Antichrist. Fourth Edition. Princeton: Princeton Univesity Press, 1974.

Kofman, Sarah. Nietzsche and metaphor. Stanford, Calif.: Stanford University Press, 1993.

Laruelle, François. Les philosophies de la différence. Paris: PUF, 1986.

Le Rider, Jacques. Nietzsche en France, de la fin du XIX siècle au temps présent. Paris: PUF, 1999.

. «Nietzsche, una pasión francesa. Cien años de recepción de Nietzsche en Francia». Revista Enrahonar. Quaderns de Filosofia 35, (2002): 89-100.

Lyotard, Jean-François. La diferencia. Barcelona: Gedisa, 1999.

Maniglier, Patrice (Dir.). Le moment philosophique des années 1960 en France. Paris: PUF, 2011.

Marton, Scarlett (Ed.). Um «frânces» entre franceses. São Paulo: Barcarolla, Discurso Editorial, 2009.

Megill, Allan. Prophets of extremity. Nietzsche, Heidegger, Foucault, Derrida. Los Angeles: University of California Press, 1987.

Pinto, Louis. Les Neveux de Zarathoustra. La réception de Nietzsche en France. Paris: Seuil, 1995. 
Nietzsche, Friedrich. Más allá del bien y del mal. Madrid: Alianza Editorial, 1990.

Ruby, Christian. Les Archipels de la Différence. Foucault-DerridaDeleuze-Lyotard. Paris: Éditions du Félin, 1989.

Ryan, Sean. «Heidegger's Nietzsche». En Woodward, Ashley (Ed.). Interpreting Nietzsche. Reception and Influence. London/ NY: Continuum, 2011.

Savater, Fernando. (1973) Así hablaba Nietzsche. Barcelona: Ediciones Áltera, 1973.

Schlechta, Karl. Le cas Nietzsche. Paris: Gallimard, 1960.

Schrift, Alan D. Nietzsche and the question of interpretation. Between Hermeneutics and Deconstruction. Chapter 1. London/NY: Routledge, 1990.

. Nietzsche's French Legacy. A genealogy of poststructuralism. NY: Routledge, 1995.

. Twentieth-Century French Philosophy. Key Themes and Thinkers. Great Britain: Blackwell Publishing, 2006.

. «Le nietzschéisme comme épistemologie. La réception française de Nietzsche dans le moment philosophique des années 1960». En Maniglier, Patrice (Dir.) Op. Cit. Chapitre IV. Paris: PUF, 2011.

Sluga, Hans. «Heidegger's Nietzsche». En A Companion to Heidegger, editado por Hubert Dreyfus y Mark Wrathall, 102-120. London: Blackwell, 2006.

Vattimo, Gianni. Dialogue with Nietzsche. Translated by William McCuaig. New York: Columbia University Press, 2005.

Winchester, James. Nietzsche's aesthetic turn. Reading Nietzsche after Heidegger, Deleuze, Derrida. Albany: State University of New York Press, 1994.

Woodward, Ashley. Understanding Nietzscheanism. Durham (UK): Acumen, 2011. 
Woodward, Ashley (Ed.). Interpreting Nietzsche. Reception and Influence. Chapter One. London/NY: Continuum, 2011.

Worms, Frédéric. Moments. La philosophie en France au xx siècle. Paris: Gallimard, 2009.

Enviado: 9 de julio de 2012 Aceptado: 21 de octubre de 2012 